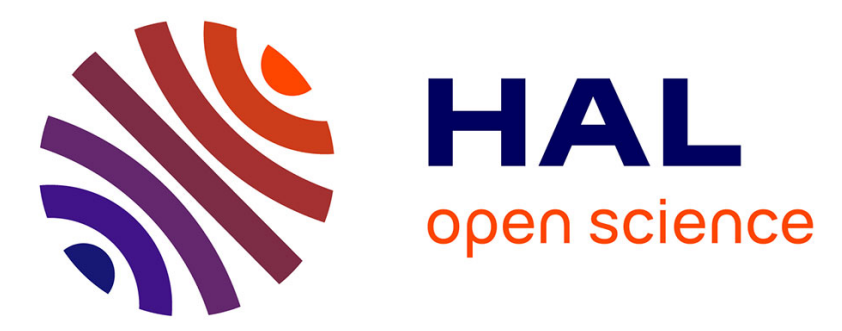

\title{
An osmotically inflatable seal to treat endoleaks of type 1, following endovascular aneurysm repair
}

Grégory Chagnon, Vincent Gaudin, Denis Favier, Laurent Orgéas, Philippe

Cinquin

\section{- To cite this version:}

Grégory Chagnon, Vincent Gaudin, Denis Favier, Laurent Orgéas, Philippe Cinquin. An osmotically inflatable seal to treat endoleaks of type 1, following endovascular aneurysm repair. Journal of Mechanics in Medicine and Biology, 2012, 12 (4), pp.1250070. 10.1142/S0219519412004958 . hal01974834

\section{HAL Id: hal-01974834 \\ https://hal.science/hal-01974834}

Submitted on 11 Jan 2019

HAL is a multi-disciplinary open access archive for the deposit and dissemination of scientific research documents, whether they are published or not. The documents may come from teaching and research institutions in France or abroad, or from public or private research centers.
L'archive ouverte pluridisciplinaire HAL, est destinée au dépôt et à la diffusion de documents scientifiques de niveau recherche, publiés ou non, émanant des établissements d'enseignement et de recherche français ou étrangers, des laboratoires publics ou privés. 


\title{
AN OSMOTICALLY INFLATABLE SEAL TO TREAT ENDOLEAKS OF TYPE 1, FOLLOWING ENDOVASCULAR ANEURYSM REPAIR
}

\author{
GREGORY CHAGNON*, VINCENT GAUDIN, DENIS FAVIER \\ and LAURENT ORGEAS \\ Université de Grenoble/CNRS \\ Laboratoire Sols, Solides, Structures, Risques \\ BP 53 - 38041 Grenoble Cedex 9, France \\ *gregory.chagnon@grenoble-inp.fr \\ PHILIPPE CINQUIN \\ Université de Grenoble/CNRS \\ TIMC-IMAG, Techniques de l'Ingénierie Médicale et de la Complexité \\ Domaine de la Merci, 38710 La Tronche, France
}

\begin{abstract}
Stent-grafts of various designs are currently used in endoluminal treatment of abdominal aortic aneurysm. Two of the remaining possible complications are endoleaks and stent migrations. To treat endoleaks of type 1, a new system is studied here: An inflatable osmotic seal. It is set up at the extremities of the endograft and swollen using osmotic process against the vessels in case of endoleak without any invasive re-intervention. Mechanical modeling of the device and finite element simulations are performed to evaluate the efficiency of the seal and the consequences on the arteries as function of the osmotic pressure.
\end{abstract}

Keywords: AAA; endoleaks; endovascular graft; seal; osmotic pressure.

\section{Introduction}

Abdominal aortic aneurysm (AAA) is a localized dilatation of the abdominal aorta. This pathology is very common in western countries, as it concerns, amongst others, nearly $5 \%$ of older men who have ever smoked. ${ }^{1}$ This enlargement of the artery can lead to rupture, with a mortality rate of $80 \%{ }^{2} \mathrm{~A}$ way to treat this illness is to deploy an endograft, held in place by a stent, in the damaged artery. This endovascular system can suffer from several possible complications. ${ }^{3}$ The main one concerns endoleaks; in a clinical study, it was noticed that endoleaks had appeared for $49 \%$ 
patients, after 7 years. ${ }^{4}$ Nevertheless, endoleaks mainly appear between the third and sixth months. When endoleaks occur, it was experimentally demonstrated that the pressure in the aneurysm is larger that the diastolic pressure. ${ }^{5}$ This pressure can lead to enlargement and rupture of the AAA, thus endoleaks have to be treated rapidly. There are many different ways to treat endoleaks, including coil embolization, placement of stent-graft cuffs and extensions, open surgical repair, and another endovascular entire graft placement. ${ }^{6}$ AAA classical treatment is the endovascular aortic aneurysm repair (EVAR). In such treatments, $49 \%$ of type I endoleaks are observed. "Fenestrated or branched EVAR" are proposed only in case of contraindications to classical EVAR, reducing the rate of type I endoleaks to about $2,5 \% .{ }^{7}$ Thus, proposing a solution to type I endoleaks for classical EVAR is very interesting, since this treatment is the one used for a majority of patients, who do not prevent EVAR contraindications.

This paper deals with the treatment of type I endoleaks by means of the addition of osmotically inflatable seals at the endograft attachment sites. The main advantage of this device would be that the endoleaks could be treated without further invasive re-intervention. The proposed system is presented in Fig. 1. At each ending of the endovascular graft, a seal is placed between the artery and the stent. This seal is initially almost not swollen but it can be fully swollen in case of detection of an endoleak by the osmotic process being activated. ${ }^{8}$ For the moment, the only marketed applications using the osmotic principle in vivo are drug delivery systems. In the application considered, direct use of physiological liquids as the solvent is envisaged. The whole designed system takes place in an artery. Plasma is $90 \%$ water, thus it is the most appropriate liquid to be used as the solvent for the osmotic process. In

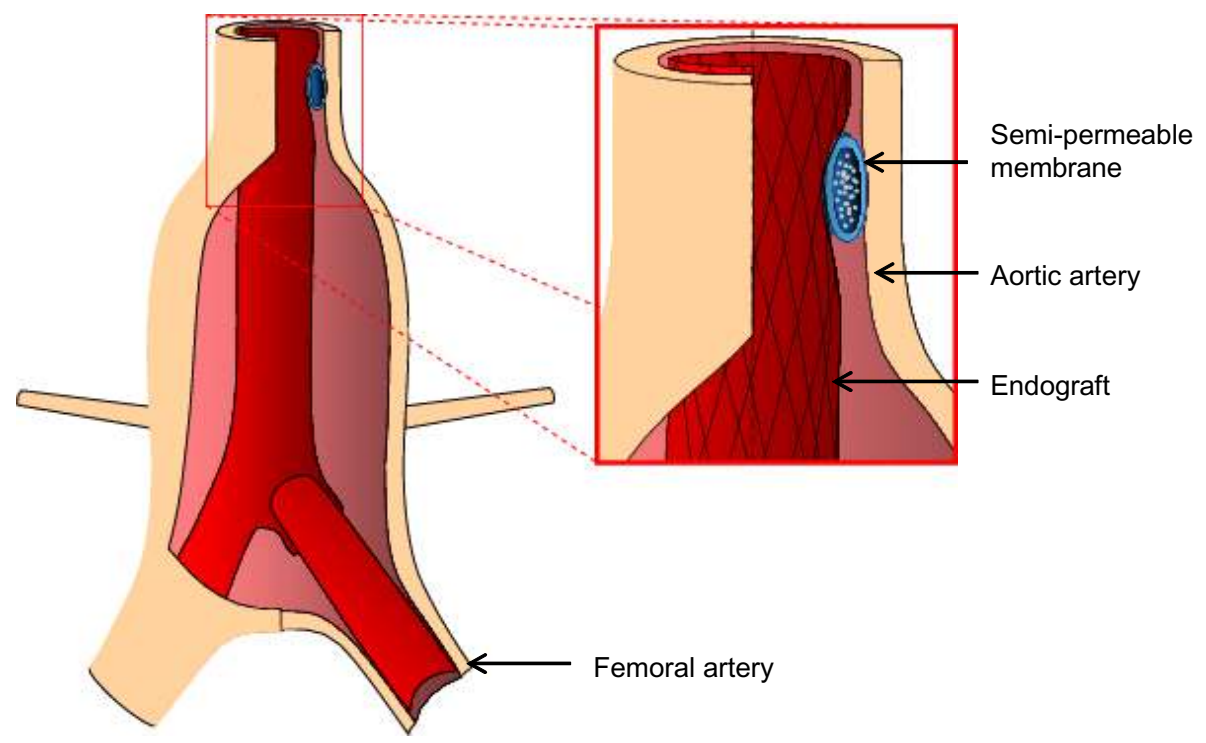

Fig. 1. (Color online) Schematic diagram of the system - Introduction of an osmotically inflatable seal between the stent and the artery at the cross link of the aorta and femoral arteries. 
addition to water molecules, the remainder is mainly composed of cells whose size (about $7 \mu \mathrm{m}$ ) is too large to have a significant osmotic effect.

In an initial approach, polysaccharide molecules are envisaged as the solute molecules to be placed inside the seal. These molecules are made of smaller components which are present in the human body and are thus well tolerated. The osmotic seal, fixed to the external endograft layer, is filled with very long polysaccharide molecules before use, the osmolarity being not too high, with chains of sizes ranging from 10 to $150 \mathrm{~kg} \mathrm{~mol}^{-1}$. This seal has to be able to inflate on demand if leakage is observed during postoperative follow-up. To achieve that goal, osmolarity inside the seal has to increase as it determines the seal pressure after osmosis has occurred. This can be done physically by dividing the large molecules by local energy delivery, by means of focused ultrasonic methods for example. Molecular scission by chemical methods could also be used as an alternative. ${ }^{8}$

The aim of the present work is to assess from numerical simulation this new system and to verify that the artery is not submitted to harmful mechanical constraints. ${ }^{9}$ In a first part, the mechanical behavior of the artery and the stent are analyzed and modeled by means of experimental data published in the literature. The semipermeable membrane, material of the seal, is modeled by means of an original experimental campaign conducted in conditions very close to the aimed application. In the second part, finite element simulations are presented for a stent graft with and without the inflatable seal in order to estimate the effectiveness of the system. The induced stresses in the aortic wall are also analyzed.

\section{Materials and Methods}

\subsection{Artery}

Arterial material is a complex multi-layered structure exhibiting complex mechanical behavior. ${ }^{10}$ Different mechanical experimental data are available concerning human aortas, in the literature, but the properties hardly vary according to the age, the sex, or the health. Nevertheless, it can be seen that aortic material, generally considered as incompressible, ${ }^{11}$ is a highly deformable material which mainly exhibits nonlinear elastic behavior. ${ }^{12}$ Many authors suggest that this material also exhibits anisotropy (see Refs. 13 and 14 for example). The framework of large deformation is used to describe this material. The isotropic strain invariants $I_{1}, I_{2}$ and $I_{3}$ (or $J$ ) are defined by:

$$
I_{1}=\operatorname{tr}(\mathbf{C}), \quad I_{2}=\frac{1}{2}\left[\operatorname{tr}(\mathbf{C})^{2}-\operatorname{tr}\left(\mathbf{C}^{2}\right)\right], \quad I_{3}=J^{2}=\operatorname{det}(\mathbf{C}),
$$

where $\mathbf{C}=\mathbf{F}^{T} \mathbf{F}$ is the right Cauchy-Green strain tensor and $\mathbf{F}$ is the deformation gradient. For fiber reinforced materials as arteries, an anisotropic approach must be used and a fiber direction vector $\mathbf{A}^{(i)}$ is defined for each fiber orientation. This leads to the introduction of a new invariant, $I_{4}^{(i)}$ which is defined as:

$$
I_{4}^{(i)}=\mathbf{A}^{(i)} \cdot \mathbf{C A}^{(i)} .
$$


Different anisotropic hyperelastic energies are proposed in the litterature. Here, the Holzapfel et al. model is used to describe aorta behavior ${ }^{10}$ :

$$
\left.W=c_{1}\left(I_{1}-3\right)+\frac{k_{1}}{2 k_{2}} \exp \left[k_{2}\left(I_{4}^{(1)}-1\right)^{2}\right]\right]+\frac{k_{3}}{2 k_{4}} \exp \left[k_{4}\left(I_{4}^{(2)}-1\right)^{2}\right],
$$

where $k_{1}, k_{2}, k_{3}$ and $k_{4}$ are material parameters. The values of the parameters are obtained from literature ${ }^{15}: C_{1}=0.11 \mathrm{MPa}, k_{1}=k_{3}=0.21 \mathrm{MPa}, k_{2}=k_{4}=1700$ and the orientation of the fibre is defined as $+/-43^{\circ}$ compared to orthoradial direction for the two artery fiber orientations. Moreover, in finite element simulations, the incompressibility condition must be carefully verified. ${ }^{16}$

In order to run the simulation, the geometrical parameters of aorta have to be given. Arterial wall thickness was taken equal to $2.22 \mathrm{~mm} .{ }^{17}$ The lumen diameter at zero pressure was determined by numerical simulation based on the fact that in vivo studies report that average lumen diameter is about $22.5 \mathrm{~mm}$ when submitted to systolic pressure. ${ }^{18} \mathrm{~A}$ simple finite element model was produced in order to define the aortic neck diameter under zero pressure, the model gives a lumen diameter of $18.16 \mathrm{~mm}$ at zero pressure.

\subsection{Stent-graft}

Endoprotheses for aortic aneurysm are typically made of a stent covered with a woven textile graft. The role of the textile graft is to prevent blood from reaching the aneurysm sac. As the static behavior of the endoprothesis fixation is the only point of interest here, the textile graft is considered to have a negligible mechanical effect and is ignored in the following.

A large range of stents exists (see for example 19). The aim of this paper is not to specify the use of one stent or another but to prove the effectiveness of the osmotic seal for a given stent. As a consequence, one representative stainless steel balloon expanding diamond-shape stent is chosen (see Fig. 2). Due to its angular repetition form, a axisymmetric equivalent modeling can be used in a first approach. The stent is, thus, considered to be equivalent to a thin cylindrical tube which mechanical behavior depends on its thickness and initial radius. ${ }^{20}$ The equivalent tube thickness is set to $0.28 \mathrm{~mm}$, based on the thickness of real aortic stents. According to manufacturer's recommendations, ${ }^{21}$ the outer stent diameter has to be set to $2 \mathrm{~mm}$ greater than the inside diameter of the aneurysm neck, it is set to $20.16 \mathrm{~mm}$. Expanding this stent radially in a finite element analysis, the equivalent cylinder to the stent is found to have the following Young modulus and Poisson ratio: $E=23 \mathrm{MPa}$ and $\nu=0.16$. An equivalent anisotropic material modeling for the tube was not necessary as the stent is submitted only to radial expansion (see Sec. 3).

\subsection{Semi-permeable membrane}

The membrane seal has two functions. First, it serves as a semi-permeable barrier to deliver mechanical energy through osmotic process. Second, it has a structural 


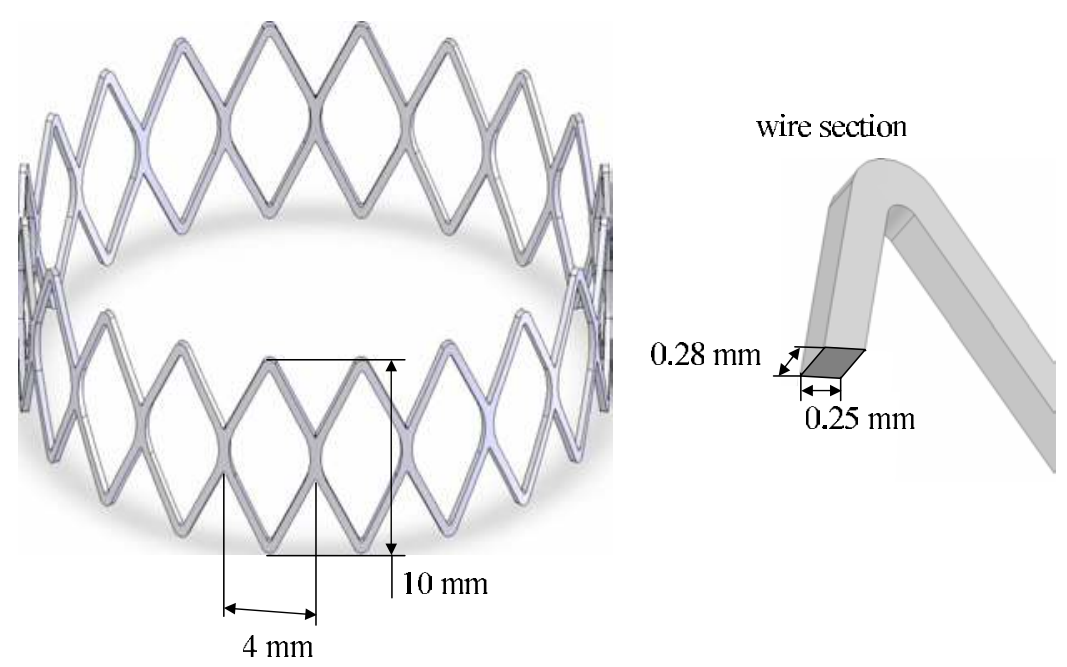

Fig. 2. (Color online) Geometry of the stent numerical model.

function, as it deforms when pressured to seal a possible endoleak. Therefore, this membrane has to be well defined, both for its molecular and mechanical functions.

Various materials can be used to produce semi-permeable membranes, the selection criteria depend first on the wanted threshold cut-off and second on its extensibility. For this study, the solvent (water) molecules have a molecular weight of $18 \mathrm{~g} \cdot \mathrm{mol}^{-1}$. From the mechanical point of view, the organic membranes seem to be soft enough for this application. Thus, a Spectra-Pore CE cellulose ester membrane with a threshold cutoff of $100 \mathrm{~g} . \mathrm{mol}^{-1}$ was chosen. This membrane is marketed in the form of $15 \mathrm{~m}$ long extruded tubes and is available in several diameters ranging from 1 to $30 \mathrm{~mm}$.

\subsubsection{Experimental device}

In order to obtain valid experimental results, it is important for the experimental conditions to be close to those of the envisaged application. For that purpose, the membrane is immersed in a solvent during mechanical testing. Thus, an original experimental system has been designed and used. ${ }^{9}$ Figure 3 shows the experimental arrangement system. A $15 \mathrm{~mm}$ outer diameter and $70 \mu \mathrm{m}$ wall thickness membrane tube, filled up with a saccharose concentrated solution, is plunged into the solvent (water) transparent tank. As saccharose has a molecular weight of $342 \mathrm{~g} . \mathrm{mol}^{-1}$ which is higher than the threshold cut-off of the selected membrane, a hydrostatic pressure is induced by the osmosis. This pressure is measured by sensor connected to the tube. Because of the immersion of the experimental system, an optical approach based on Digital Image Correlation (DIC) technique was used in order to estimate the strain fields of deformed tubes during the tests. Hence, before introduction of the membrane into the apparatus, the outer surface of the tube was covered with a random pattern of speckles of black paint. The digital camera (CCD) takes pictures at regular time 


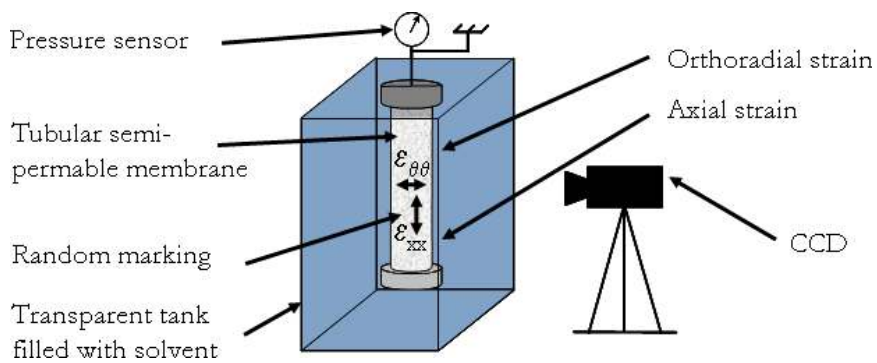

Fig. 3. (Color online) Schematic diagram of the experimental setup including data acquisition system.

intervals while the membrane deforms due to the rise in hydrostatic pressure $\Delta P$. The DIC software: 7D is used for the analysis. ${ }^{22,23}$ This deformation field is calculated from images projection on a plane parallel to the CCD surface; consequently, only the area close to the cylinder's axis can be considered and analyzed. Hence, it was possible to estimate from this technique the axial $\varepsilon_{x x}$ and the orthoradial $\varepsilon_{\theta \theta}$ logarithmic strain on the surface of the tube. As the tube ratio thickness/diameter is very small, this allows to assume that $\varepsilon_{x x}$ and $\varepsilon_{\theta \theta}$ are good estimate of the strain field inside the tube. Since the tube remains perfectly cylindrical during deformation in the observation area, it is possible to deduce from the internal pressure, the stress state, i.e. the axial and orthoradial Cauchy stress components.

\subsubsection{Experimental results}

Figure 4 shows the evolution of $\Delta P$ as function of the orthoradial strain $\varepsilon_{\theta \theta}$ for various initial differential concentrations $\Delta C_{0}$ of saccharose in the osmotic tube. The

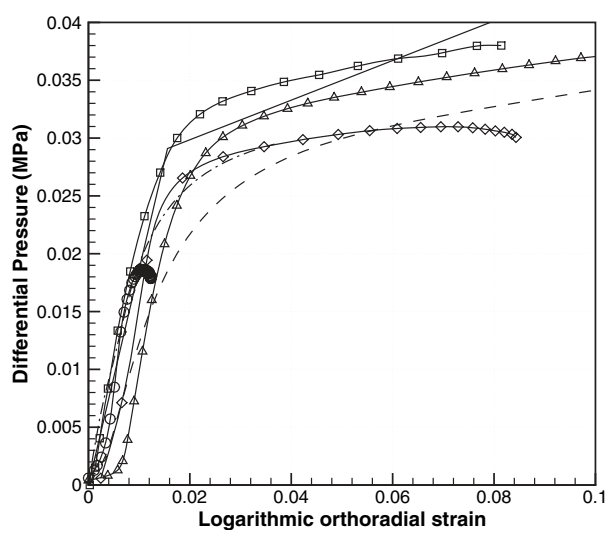

(a)

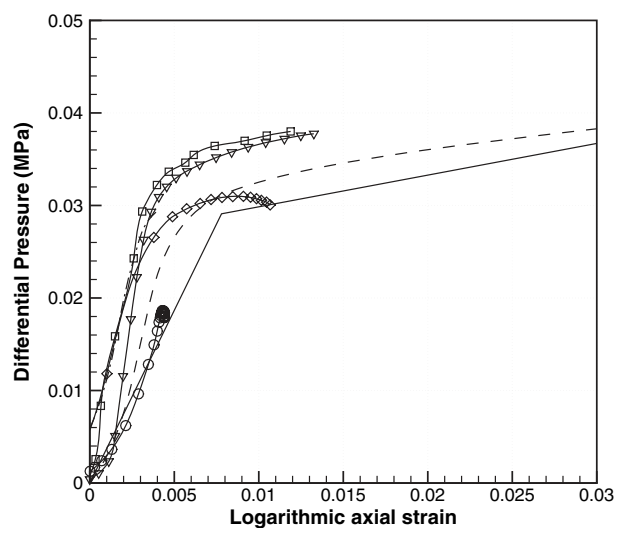

(b)

Fig. 4. Evolution of the observed differential pressure $\Delta P$ as function of the logarithmic (a) orthoradial $\varepsilon_{\theta \theta}$ and (b) axial $\varepsilon_{x x}$ strains for different solute concentrations $\Delta C_{0}:(-\circ-) 0.01 \mathrm{~mol}^{-1},(-\diamond-) 0.02 \mathrm{~mol}$.

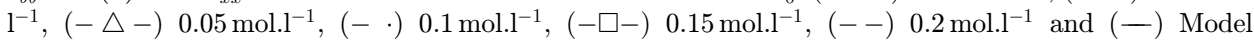
prediction. 


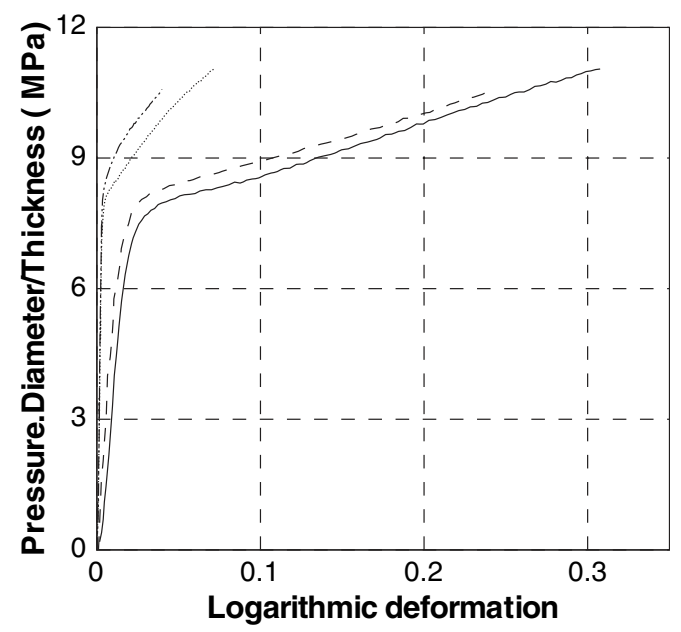

Fig. 5. Influence of specimen size on experimental results: $15 \mathrm{~mm}$ specimen $(-)$ longitudinal direction $(-\cdots-)$ circumferential direction and $20 \mathrm{~mm}$ specimen $(--)$ longitudinal direction $(\cdots)$ circumferential direction.

different concentrations lead to different strain rates (from $2.1 \times 10^{-8} \mathrm{~s}^{-1}$ for the orthoradial strain rate for $\Delta C_{0}=0.01 \mathrm{~mol} . \mathrm{l}^{-1}$ to $8.6 \times 10^{-6} \mathrm{~s}^{-1}$ for $\Delta C_{0}=$ $\left.0.2 \mathrm{~mol} . \mathrm{l}^{-1}\right)$. Whatever is the concentration, the pressure-strain curves are very similar, so that the membrane mechanical behavior can be considered as independent of the strain rate, the fluctuations relay on experimental dispersion. Moreover, Fig. 5 presents a comparison of strain-pressure curves for the two different geometries: a $15 \mathrm{~mm}$ diameter and a $20 \mathrm{~mm}$ diameter membrane with the same thickness $70 \mu \mathrm{m}$. In order to be geometrical parameters independent, the pressure is multiplied by the diameter and divided by the thickness of the tube. It is noted that for these two given geometries the results are identical. This permits to consider the problem as geometry independent, and to fit material properties. Figure 6 represents Von-Mises stress versus Von-Mises strain for all $\Delta C_{0}$ tested.

\subsubsection{Modeling}

The observed behavior can be reasonably well modeled by an isotropic elastoplastic model with a isotropic linear hardening. ${ }^{24}$ This model is defined by four material parameters: Young's modulus $E$ and Poisson ratio $\nu$ for the elastic part, plastic coefficient $K_{Y}$ and elastic limit $\sigma_{Y}$ for the plastic part. These parameters are fitted on the data for axial and orthoradial strain components as functions of pressure: $E_{m}=$ $200 \mathrm{MPa}, \nu_{m}=0.43, \sigma_{Y}=18.35 \mathrm{MPa}$ and $K_{Y}=16 \mathrm{MPa}$ are obtained. Model predictions are compared with experimental results in Fig. 6. Rather good agreement is obtained for the von-Mises stress and the radial strain (see Fig. 4). The agreement for axial behavior is less good, this could be due to the assumptions of isotropy or incompressibility in the plastic deformation model. Nevertheless, the model matches 


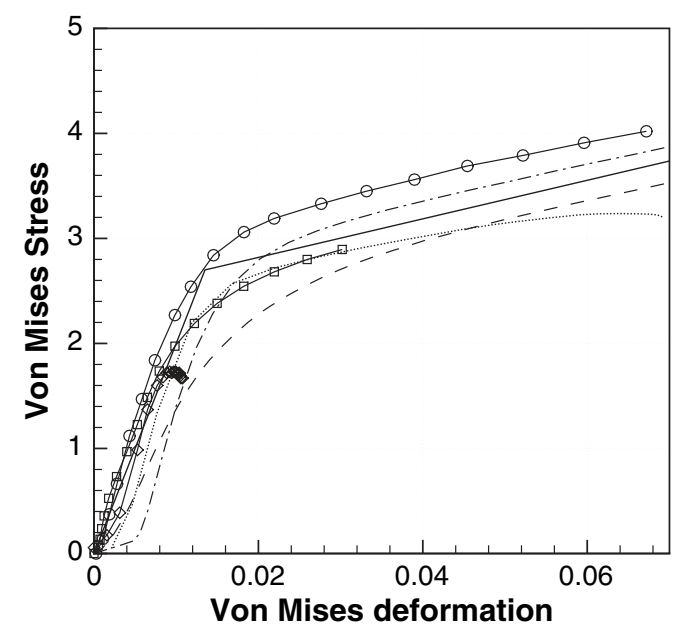

Fig. 6. Evolution of the Von-Mises stress according to Von-Mises strain in the membrane for different solute concentration $\Delta C_{0}:(-\diamond-) 0.01 \mathrm{~mol}^{-1} \mathrm{l}^{-1},(\cdots) 0.02 \mathrm{mol.} \mathrm{l}^{-1},(-\cdot) 0.05 \mathrm{~mol}^{-1} \mathrm{l}^{-1},(-\square-) 0.1 \mathrm{~mol} . \mathrm{l}^{-1}$, (- ० -) 0.15 mol. $\mathrm{l}^{-1},(--) 0.2 \mathrm{~mol} . \mathrm{l}^{-1}$ and (-) Model simulation.

the observed behavior well enough to be used to investigate the behavior of the proposed seal.

\subsection{Finite element modeling}

In the intended application, the inflatable membrane seal has a toroidal geometry, as illustrated in Fig. 7. It is defined by its great diameter $D_{m}=24.5 \mathrm{~mm}$, its wall thickness $e_{m}=0.07 \mathrm{~mm}$, its height $h_{m}=2 \mathrm{~mm}$ and the radius of curvature $r_{m}=0.2 \mathrm{~mm}$.

The effectiveness of the osmotic seal in increasing the contact pressure between the stent and the artery is studied. Simulations are performed with and without the seal, so as to measure the utility as well the influence of that seal. The problem was assumed to exhibit revolution orthotropy, so that, an axi-symmetric representation of an endograft in an aneurysm is used. The two systems (a) without and (b) with seal are presented in Fig. 8. The different problems were solved with the finite

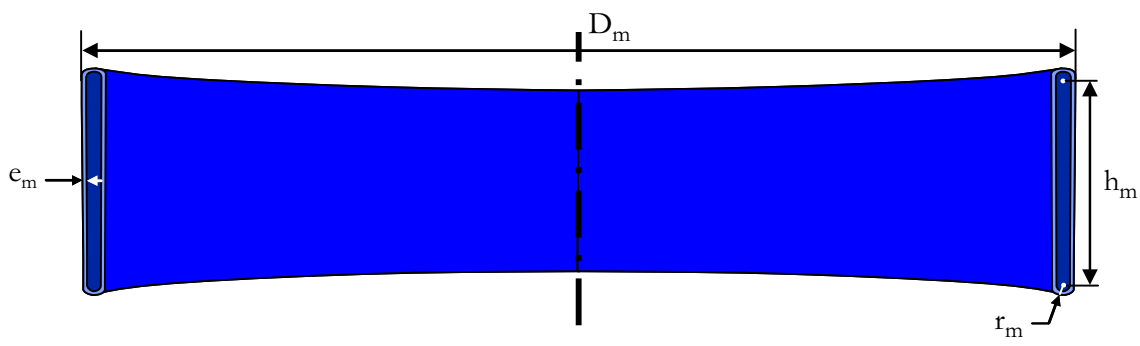

Fig. 7. (Color online) Membrane seal geometry. 


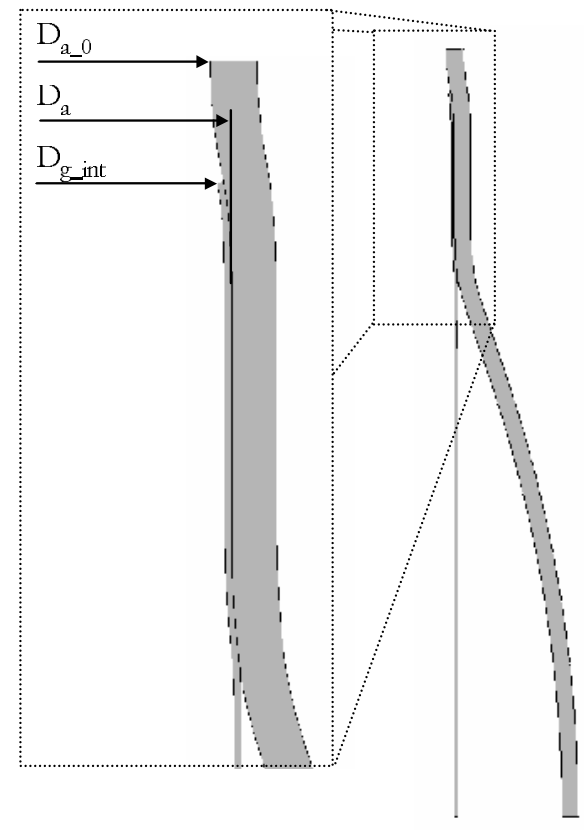

(a)

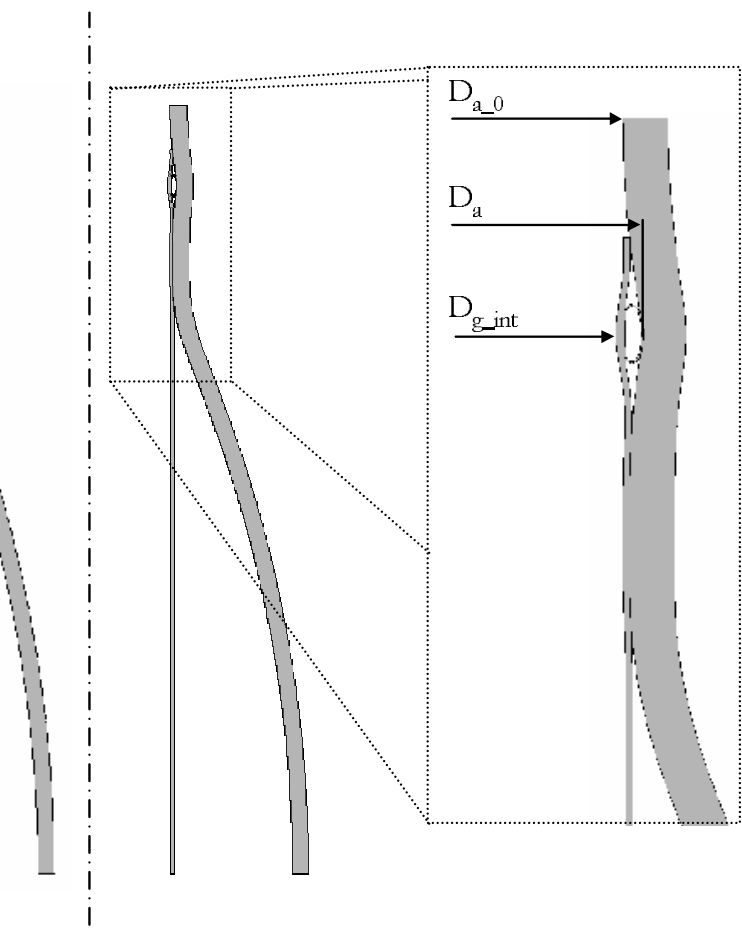

(b)

Fig. 8. Deformed shape of the whole system (a) without and (b) with seal at $0.1 \mathrm{MPa}$ inflation pressure $\mathrm{P}$ and $0.01 \mathrm{MPa}$ systolic blood pressure. Zooms show the graft fixation area and characteristic dimensions.

element software Abaqus. Quadratic elements are used for the membrane and the stent, and hybrid (quadratic in displacement and linear in pressure) elements for the artery to deal with the assumed incompressibility. Membrane seal is considered to be stuck to the stent. The upper and lower extreme aortic surfaces are axially fixed as supposed by many authors (see for example 25). Two types of load are applied to the model, viz. blood pressure and seal inflated pressure.

Graft deployment has not been simulated. Instead, a particular sequence has been designed to simulate the set up of this graft inside the artery:

- A high pressure is first applied inside the artery wall to increase the artery inner diameter to allow the introduction of the graft without contact;

- The defining contact conditions existing between the graft and the living tissue are obtained by decreasing the applied pressure to a physiologic systolic pressure (0.017 MPa);

- Then, the influence of the inflated pressure P inside the seal can be evaluated; different inflating pressures represent different solute molar concentrations.

An illustration of the pressure conditions is presented in Fig. 9. 


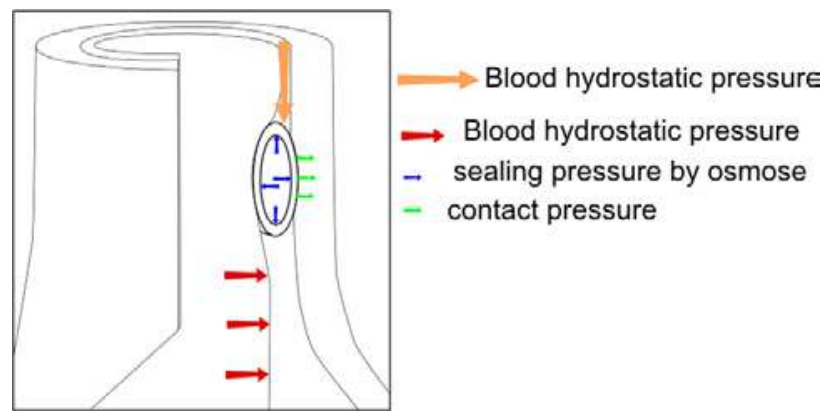

Fig. 9. (Color online) Description of the pressure conditions applied on the system.

\section{Results}

The deformed shapes of the systems are shown in Fig. 8 for systolic pressure when the seal inflated pressure is $0.01 \mathrm{MPa}$. The seal locally increases deformation of the artery. The contact pressure between the graft and the neck of the aneurysm with and without seal membrane is plotted in Fig. 10. For the model with seal, the contact pressure profile is obtained from an inflation pressure level $\Delta P=0.1 \mathrm{MPa}$.
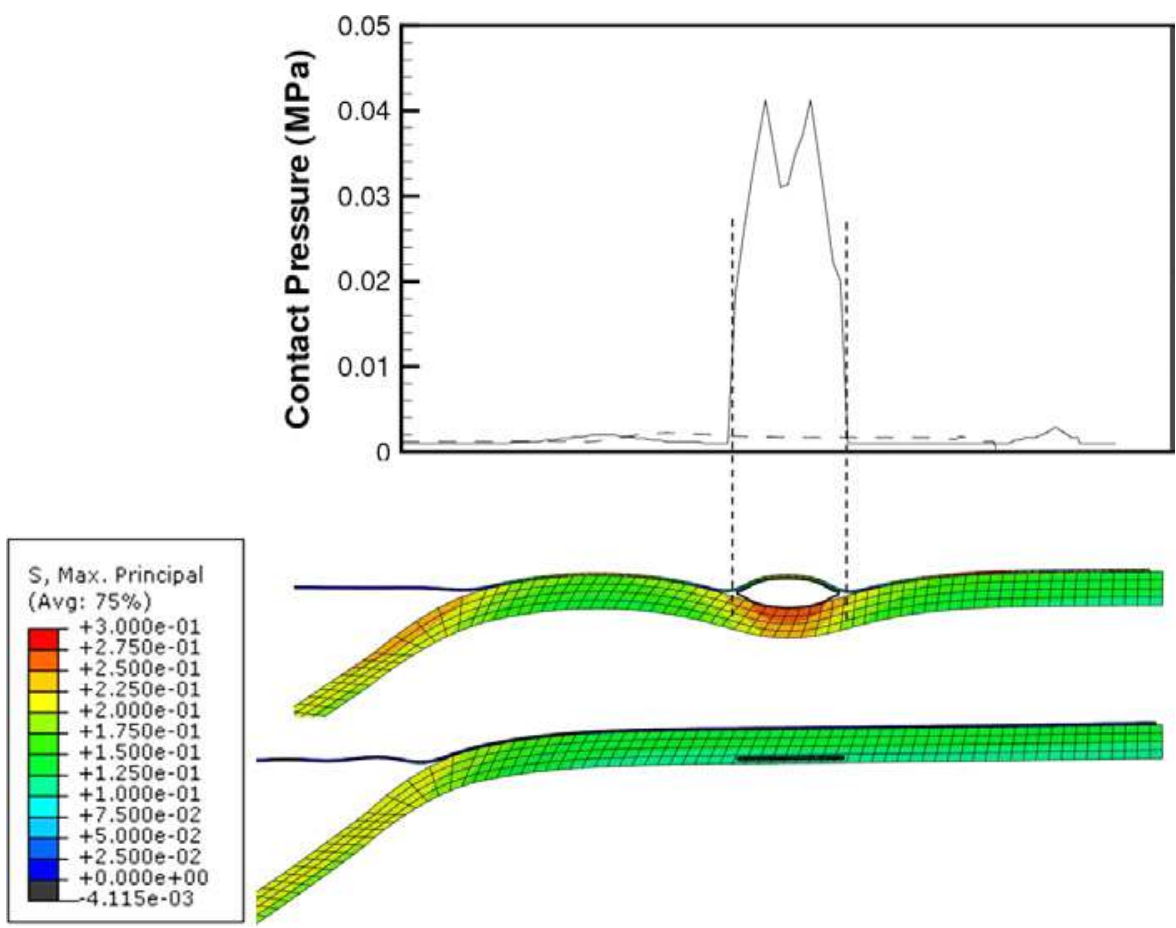

Fig. 10. (Color online) Evolution of the contact pressure along the axial position from the middle of the aneurysm: Comparison between the models with seal filled at $0.01 \mathrm{MPa}(-)$ and at $0.08 \mathrm{MPa}(-\cdot)$ and without seal (--). Color maps show the shape and maximal principal stress of the two models. 


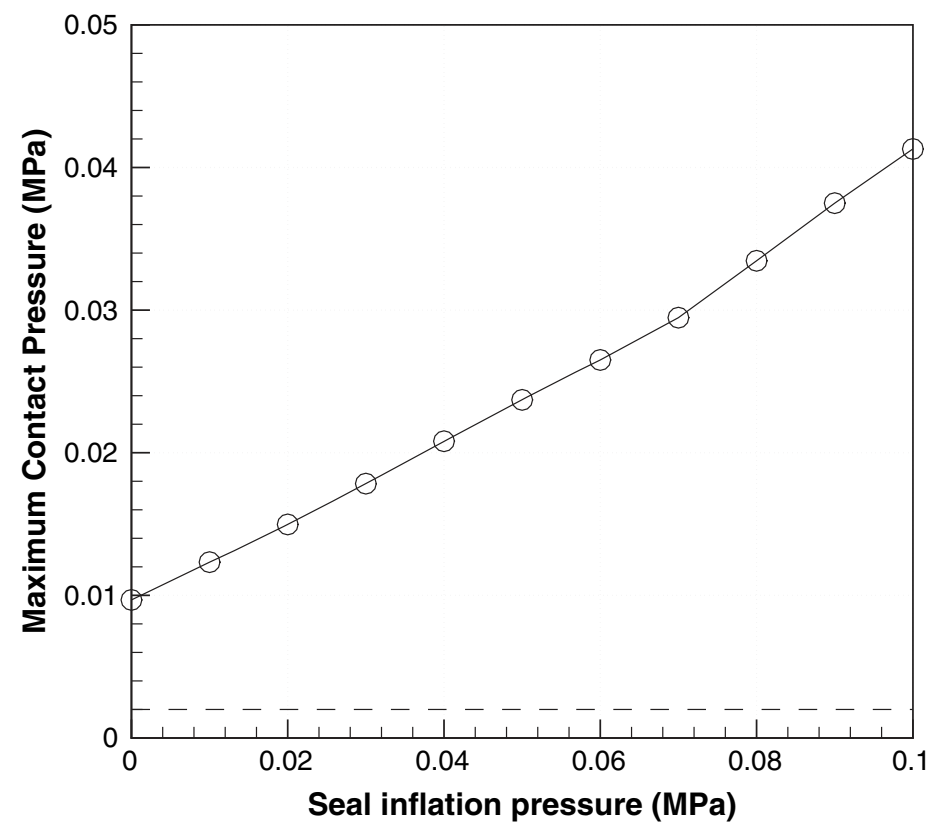

Fig. 11. Maximum contact pressure versus seal inflation pressure $\Delta P$ at the centre of the seal $(-\circ-)$, contact pressure without seal $(--)$.

The maximum contact pressure level is observed near the centre of the seal contact, and depends on the inflation pressure $\Delta P$, as shown in Fig. 11. It can be seen that for an inflation pressure $\Delta P$ higher than $0.01 \mathrm{MPa}$, the contact pressure is higher with the seal than without: for example, at $\Delta P=0.1 \mathrm{MPa}$, the contact pressure is twenty times higher. The contact pressure can be controlled in order to limit endoleaks. The pressure in the seal is greater than the applied pressure during experimental tests, but it is not significant. The pressures should not be compared but the orthoradial stresses in the seal which stay highly lower than during experimental tests, then there is no failure-risk in the seal because of pressure. Moreover, the integrity of the artery must be verified, the maximal principal stress in the arterial wall is presented in Fig. 12 according to the seal inflation pressure $(\Delta P)$. It appears that the stress does not exceed $260 \mathrm{kPa}$ even for the highest inflation pressures, this ensures that the seal does not damage the artery.

Apart from increasing contact pressure, this system also changes the geometry of the graft fixation area; changes occur in some geometric dimensions, initial lumen diameter $D_{a 0}$, aorta diameter $D_{a}$, and smallest lumen diameter after graft deployment $D_{g-i n t}$. Changes in the cross-section for blood flow can be characterized by the ratio of current to initial cross-section, $S / S_{0}$. The dependencies of $D_{a} / D_{a 0}$ and $S / S_{0}$ on inflation pressure are shown in Fig. 13, the different values without the seal are also shown.

Concerning lumen diameter, it can first be seen that both models provoke an increase. For the model with seal, this increase depends on the inflation pressure; 

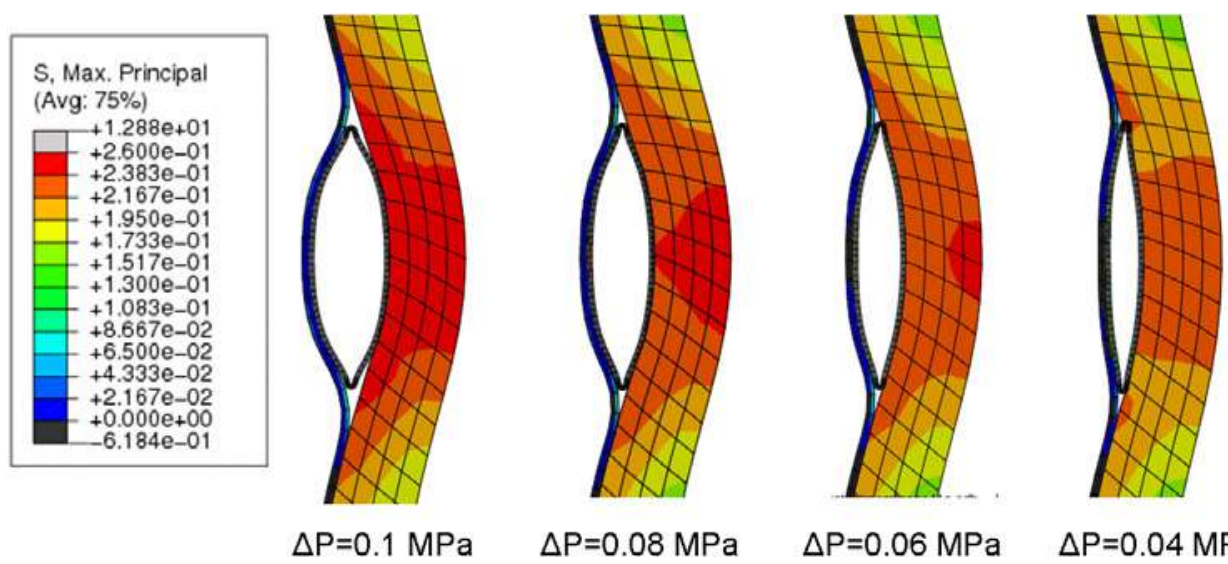

$\Delta \mathrm{P}=0.04 \mathrm{MPa}$

Fig. 12. (Color online) Maximum principal stress in the artery according to the seal inflation pressure.

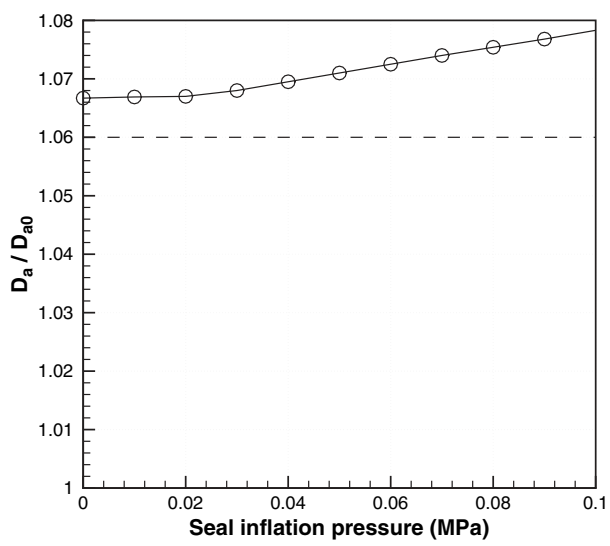

(a)

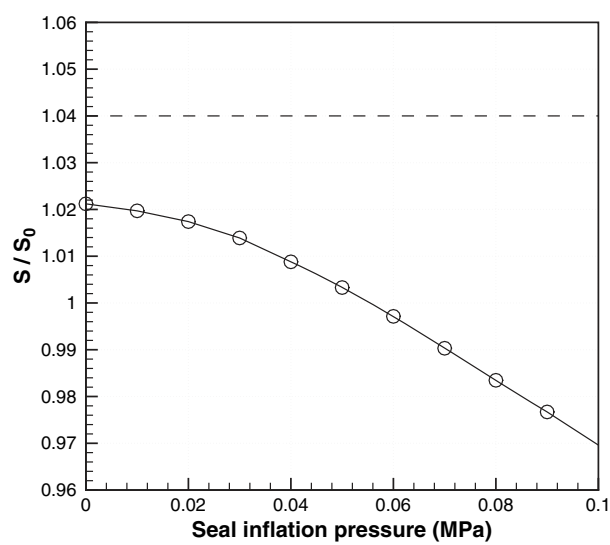

(b)

Fig. 13. Dimension evolution function of inflating pressure (--) without seal and (- o - ) with seal, (a) variation of internal artery diameter and (b) variation of blood cross-section.

from $6.8 \%$ for $\Delta P=0$ to $7.9 \%$ for $\Delta P=0.1 \mathrm{MPa}$. It can also be seen that the graft with seal produces a slightly larger increase in diameter than does the classical graft, whatever the inflating pressure. The cross-sectional area blood flow, is also affected by the presence of the seal, for an endograft, it tends to increase by up to $4 \%$ under systolic pressure, whereas the seal gives a slight reduction, when inflation pressure is larger than 0.05 $\mathrm{MPa}$, nevertheless this increase stays lower than $3 \%$.

\section{Conclusion}

An inflatable system which is positioned at the extremities of an aortic aneurysm endograft to increase resistance to blood leakage was presented. The system which 
operates by osmosis is used if endoleaks are detected during postoperative imaging. The level of the osmotic pressure and thus of the sealing pressure would be adjusted by controlling osmolarity inside the seal. Thus, the inflation can be initiated if and when required (many times after endograft fixation) without surgery.

In this article, a numerical simulation method has been used to study the mechanical performance of the device. It has been verified in an example that the artery is largely unaffected by the seal, a small increase in stresses is observed but this should be without consequence on artery integrity. It demonstrates that sealing is reinforced, as the contact pressure between the graft and the arterial wall is increased. In addition, the consequences of the pressure of the inflatable seal on the physiological components (arterial stress and dimensions) seem to be small enough to be well tolerated. In fact, such an osmotic seal must be adapted to the stent being used, but it is adaptable to any stent.

On the basis of the encouraging results, an experimental program is planned with in vivo experiments, in order to confirm the benefits of the presence of the seal at the neck of the aneurysm.

\section{Acknowledgments}

We thank Paolo Porcu and Jean-Luc Magne, surgeons at cardiovascular service at the hospital of Grenoble, France; for our helpful discussions on AAA and endoprothesis systems.

\section{References}

1. Lederle FA, Kane RL, MacDonald R, Systematic review: Repair of unruptured abdominal aortic aneurysm, Ann Intern Med 146:735-741, 2007.

2. Adam D, Mohan I, Stuart W, Bain M, Bradbury A, Community and hospital outcome from ruptured abdominal aortic aneurysm within the catchment area of a regional vascular surgical service, J Vasc Surg 30:922-928, 1999.

3. Vorp DA, Biomechanics of abdominal aortic aneurysm, J Biomech 40:1887-1902, 2007.

4. Alric P, Hinchliffe RJ, Wenham PW, Whitaker SC, Chuter TAM, Hopkinson BR, Lessons learned from the long-term follow-up of a first-generation aortic stent graft, J Vasc Surg 37:367-373, 2003.

5. Schurink G, Aarts NJ, Wilde J, van Baalen JM, Chuter TAM, Schultze Kool LJ, van Bockel JH, Endoleakage after stent-graft treatment of abdominal aneurysm: Implications on pressure and imaging-an in vitro study, J Vasc Surg 28:234-241, 1998.

6. Katzen BT, MacLean AA, Complications of endovascular repair of abdominal aortic aneurysms: A review, Cardio Vasc Inter Rad 29:935-946, 2006.

7. Muhs BE, Verhoeven EL, Zeebregts CJ, Tielliu IF, Prins TR, Verhagen HJ, van den Dungen JJ, Mid-term results of endovascular aneurysm repair with branched and fenestrated endografts, J Vasc Surg 44:9-15, 2006.

8. Cinquin P, Cinquin O, Favier D, Orgéas L, Pecher M, Pujol S, Micro-muscle in biological medium, Patent n WO03007844, 2003.

9. Gaudin V, Contribution à l'étude de micromuscles artificiels activables par pression osmotique et implantables en milieu biologique, Ph. D. Thesis, University of Grenoble, France, 2007. 
10. Holzapfel GA, Gasser TC, Ogden RW, A new constitutive framework for arterial wall mechanics and a comparative study of material models, J Elast 61:1-48, 2000.

11. Carew TE, Vaishnav RN, Patel DJ, Compressibility of the arterial wall, Circ Res 22:61-68, 1968.

12. Vito RP, Dixon SA, Blood vessel constitutive models, Annu Rev Biomed Eng 5:413-439, 2003.

13. Olsson T, Stalhand J, Klarbring A, Modeling initial strain distribution in soft tissues with application to arteries, Biomech Model Mechanobiol 5:27-38, 2006.

14. Rajagopal K, Bridges C, Rajagopal KR, Towards an understanding of the mechanics underlying aortic dissection, Biomech Model Mechanobiol 6:345-359, 2007.

15. Rodriguez JF, Martufi G, Doblare M, Finol EA, The effect of the material model formulation in the stress analysis of abdominal aortic aneurysms, Ann Biomed Eng 37:2218-2221, 2009.

16. Toungara M, Chagnon G, Geindreau C, Numerical analysis of the wall stress in abdominal aortic aneurysm: Influence of the material model near-incompressibility, J Mech Med Biol 12:1250005-1-19, 2012.

17. Li AE, Kamel I, Rando F, Anderson M, Kumbasar B, Lima JA, Bluemke DA, Using MRI to assess aortic wall thickness in the multiethnic study of atherosclerosis: Distribution by race, sex, and age, Am J Roentgenol 182:593-597, 2004.

18. Rao Vallabhaneni S, Harris PL, Lessons learnt from the eurostar registry on endovascular repair of abdominal aortic aneurysm repair, Eur J Radiology 39:34-41, 2001.

19. Stoeckel D, Pelton A, Duerig T, Self-expanding nitinol stents: Material and design considerations, Eur Radiol 14:292-301, 2004.

20. Li Z, Kleinstreuer C, Blood flow and structure intercations in a stented abdominal aortic aneurysm model, Med Eng Phys 27:369-382, 2005.

21. Gore, Gore excluder bifurcated endoprosthesis: Instructions for use, 2005.

22. Vacher P, Dumoulin S, Morestin F, Mguil-Touchal S, Bidimensional strain measurement using digital images, Proc Mech Eng C 213:811-817, 1999.

23. Meunier L, Chagnon G, Favier D, Orgéas L, Vacher P, Mechanical experimental characterisation and numerical modelling of an unfilled silicone rubber, Polym Test 27:765-777, 2008.

24. Lemaitre J, Chaboche JL, Mechanics of Solid Materials, Cambridge University Press, 1990.

25. Raghavan M, Vorp DA, Toward a biomechanical tool to evaluate rupture potential of abdominal aortic aneurysm: Identification of a finite strain constitutive model and evaluation of its applicability, J Biomech 33:475-482, 2000. 